\title{
Modern technology in supervision of parturition to prevent piglet mortality
}

\author{
Claudio Oliviero*1, Mari Heinonen ${ }^{1}$, Matti Pastell2, Jukka Heikkonen³, \\ Anna Valros ${ }^{4}$, Outi Vainio ${ }^{5}$ and Olli Peltoniemi ${ }^{1}$
}

\author{
Address: ${ }^{1}$ University of Helsinki, Faculty of Veterinary Medicine - Department of Production Animal Medicine, 04920 Saarentaus, Finland, \\ ${ }^{2}$ University of Helsinki - Department of Agrotechnology, 00014 Helsinki, Finland, ${ }^{3}$ Helsinki University of Technology - Laboratory of \\ Computational Engineering, 02150 Espoo, Finland, ${ }^{4}$ University of Helsinki, Faculty of Veterinary Medicine - Research Centre for Animal Welfare, \\ Department of Production Animal Medicine, 00014 Helsinki, Finland and ${ }^{5}$ University of Helsinki, Faculty of Veterinary Medicine - Department \\ of Equine and Small Animal Medicine, 00014 Helsinki, Finland \\ Email: Claudio Oliviero* - claudio.oliviero@helsinki.fi \\ * Corresponding author
}

from Perinatal Death In Domestic Animals: The 20th Symposium of the Nordic Committee for Veterinary Scientific Cooperation (NKVet) Reykjavik, Iceland. 26-27 April 2007

Published: 12 December 2007

Acta Veterinaria Scandinavica 2007, 49(SuppI I):SI2 doi:I0.II86/I75I-0I47-49-SI-SI2

This abstract is available from: http://www.actavetscand.com/content/49/SI/SI2

(C) 2007 Oliviero et al; licensee BioMed Central Ltd.

\section{Introduction}

Perinatal mortality in the pig is still an unsolved problem. Causes of mortality in this phase are not always well known due to unreliability of the diagnosis made by a farmer. However, valuable scientific data are available from previous research. Crushing has been found to be an important cause of perinatal death, but often it is only the last event of a series of previous causal effects, as some studies have demonstrated $[1,2]$. Hypothermia and starvation are usually underestimated, but frequently they are the direct, or the main predisposing cause of perinatal mortality.

Human supervision at farrowing can halve the piglets' perinatal mortality [3]. However this would heavily affect the economy of the herd, due to high costs of workers. In the near future, modern technology could be used to better supervise farrowing and reduce the piglet mortality, without being too costly. Predictive signs of farrowing are the increase of sow's body temperature [4] and, specially, the increase of sow's activity due to nest-building behaviour $[5,6]$.

In the "Sikatekno project" (Helsinki University - Faculty of Veterinary Medicine) we are testing sensors for measuring movement in order to predict the beginning of farrow- ing and thus alert the farmer for supervision. We are investigating also the use of thermal cameras aimed to discover piglets suffering of hypothermia in the first days after farrowing. This would allow a prompt and appropriate treatment of weak newborn piglets, improving their chances of survival.

\section{Materials and methods}

Photocell sensors were used to detect movements of 8 sows in crates (from 5 days before farrowing to 3 days after). The sensors were placed so that each time the sow was standing, the photocell's beam was intercepted and the signal acquired by a datalogger and measurement software (Biopac System Inc, USA). Additionally, an elastic electret film sensor (Emfit Oy, Finland) was placed on the floor under the sows $(n=4)$. Any movements of the sows produced a physical stress of the sensor, which generated a corresponding electrical signal recorded by the connected datalogger and software (Biopac System Inc, USA).

We investigated also the pre-farrowing rise of sows' body temperature, using a thermal camera (IR Flex Cam, Infrared Solutions Inc, USA). Repeated pictures of the sows' head were obtained daily from 5 days before farrowing. Average skin temperature of the area around the eyes was 
obtained with the thermal camera software (Flex View, Infrared Solutions Inc, USA).

Moreover, the thermal camera was used to compare totalbody skin temperature of weak newborn piglets to healthy ones.

All the results were subjected to analysis of variance with repeated measurements (GLM repeated measurements).

\section{Results}

The average of minutes/hour spent by sows standing was significantly higher in the $24 \mathrm{~h}$ before farrowing than all the other periods monitored $(\mathrm{p}<0.001 ; \mathrm{n}=8)$.

The elastic electret film sensor recorded a significantly higher amount of peaks in the $24 \mathrm{~h}$ before farrowing than all the other periods monitored ( $\mathrm{p}<0.001 ; \mathrm{n}=4)$.

Skin temperature of the area around the eyes increased by $0.98 \pm 0.31^{\circ} \mathrm{C}($ mean $\pm \mathrm{SD} ; \mathrm{n}=4)$ from day -5 to day 0 .

Weak piglets, showing difficulties to move and with poor response to external stimuli, had an average total-body skin temperature lower than healthy piglets $(\mathrm{p}<0.001 ; \mathrm{n}$ $=14)$.

\section{Discussion}

Our preliminary findings show the possibility of developing a sensor-software system that could be used to predict the beginning of farrowing. This system could be integrated with more sophisticated devices, like thermal camera, to facilitate the detection of weak piglets suffering from hypothermia in the first hours of life.

\section{References}

I. Edwards SA: Perinatal mortality in the pig: environmental or physiological solutions? Liv Reprod Sci 2002, 78:3-12.

2. English PR: Mortality and variation in growth of piglets: a study of predisposing factors with particular reference to sow and piglet behaviour. In PhD thesis University of Aberdeen; 1969.

3. White KR, Anderson DM, Bate LA: Increasing piglet survival through an improved farrowing management protocol. Can J Anim Sci 1996, 76:491-495.

4. Hendrix WF, Kelley KW, Gaskins CT, Bendel RB: Changes in respiratory rate and rectal temperature of swine near parturition. J Anim Sci 1978, 47:188-191.

5. Bradshaw RH, Broom DM: A comparison of the behaviour and performance of sows and piglets in crates and oval pens. Anim Sci 1999, 69:327-333.

6. Hartsock TG, Barczewski RA: Prepartum behavior in swine: effects of pen size. J Anim Sci 1997, 75:2899-2904.

\section{Publish with Biomed Central and every scientist can read your work free of charge}

"BioMed Central will be the most significant development for disseminating the results of biomedical research in our lifetime. " Sir Paul Nurse, Cancer Research UK

Your research papers will be:

- available free of charge to the entire biomedical community

- peer reviewed and published immediately upon acceptance

- cited in PubMed and archived on PubMed Central

- yours - you keep the copyright

Submit your manuscript here:

http://www.biomedcentral.com/info/publishing_adv.asp 